\title{
2. THE CONCEPT OF "MODELARIUM" AND ITS IMPACT ON CREATIVITY AND ARTISTIC EDUCATION
}

\author{
Bujar Bajçinovci ${ }^{104}$ \\ Florina Jerliu $^{105}$
}

\begin{abstract}
Students and Teachers are an epic symbiosis in process of direct learning and academic advancement. Nowadays, this interaction is more bonded and interdependent with technology and equipment's, which in a whole system expands learning horizons. The digital era has introduced in the education system new modes of learning, a new way of life and style in schooling. This phenomenon changed the methods of teaching in universities, where lectures were accompanied with concrete explanations of works in modeling, in structural and conceptual sense. The relationship between a student of architecture and teachers broadened with introduction of computer aided modeling and simulation tools to construct those ideas into the reality. The study presented in this paper investigates conceptual methods in art, architecture, creativity and innovation in academic education, focusing on interactive teaching issues, and methods. The research methods consist of empirical observation carried out during 25 years of experience in academia, and direct observation of teaching methods. The purpose of this paper is to examine the evolutive process in teaching relations between architectural students and teachers, with the focus in educational competencies and communication skills. Findings indicate that through artistic concepts of "Modelarium" as an unconventional learning space, a tool and space that enables the partnership. An informal meeting place for artistic interaction, but, concurrently it is a formal part of the educational system in architectural studies, a strategy by which we can bring more: time, conceptual awareness of space and interactive teaching in architecture, which bonds multidimensional threads between students and teachers; thus, fostering a powerful sense of partnership, avoiding boredom and passive learning, while facing the challenges, associated with the development of technology, life style, real issues and global world trends. Research suggests that uniform and/or partially new strategy, cannot respond to all specific issues faced by students in day to day basis. Therefore, new teaching strategies must involve new partnerships, a brand new and a redefined role as a holistic symbiosis, as an response to a less functional and/or conventional academic system. Partnership, a new working symbiosis between students and teachers is an answer to the needs of working together simultaneously towards continuous improvement of academia processes.
\end{abstract}

Key words: Education, Architecture, Modeling, Art, Academia, Partnership

\section{Introduction}

Students and Teachers are an epic symbiosis in process of direct learning and academic advancement. What is the essence of this interaction? Surely, it is not a question with a simple answer. Nowadays, this interaction is more bonded and interdependent with technology and equipment's, which in a whole system expands learning horizons. In the field of architecture, introduction of computer aided modelling and simulation tools has opened new opportunities for the artistic conception and production of architectural projects. Architects, known as

\footnotetext{
${ }^{104}$ Associate Professor PhD., University from Prishtina, Republic of Kosovo, email: bujar.bajcinovci@unipr.edu

${ }^{105}$ Associate Professor PhD., University from Prishtina, Republic of Kosovo, email: florina.jerliu@uni-pr.edu
} 
among the preeminent computer users at all development levels, became essential also to the birth of good software, which suit to their need for artistic expression, validating thus the thought that "the discerning users [are those] who help foster software quality" (Toriya, 2008). In this context, the question on what should be exactly the role of computer in architectural design and teaching, remains open since the revealing of ideas for Computer Aided Design in architectural schools. Architectural design, interior design, urban planning and design, as well as other disciplines involved in architecture are the most interesting fields for exploring interactive conceptual varieties, which are presented in a contemporary process of learning.

Hence, we argue that for the future understanding of academia's role, it is crucial to be respected and implemented a non-orthodox curricula or a common ways of transmitting knowledge, which will have direct impact on quality and teaching diversity. It is important to note that this would imply an understanding of digital architectures, which are "defined by computationally based processes of form origination and transformations, i.e. the processes of digital morphogenesis, where the plural (architectures) emphasizes multiplicities inherent in the logics of the underlying computational concepts, such as topological geometries, isomorphic polysurfaces, motion kinematics and dynamics, key shape animation (metamorphosis), parametric design, genetic algorithms (evolutionary architectures), performance" (Kolarević, 2005).

The second component, crucial to the academic stimulation of artistic creativity in students of architecture is the comprehension of 'trend' and the background of its absorption. The intangible beliefs and motifs of society over centuries have always had the great impact on values of what is a trend, and modern. A great expression of art, architecture and education has over millenniums emerged as a consequence of development of unorthodox ideas, which became a measure for society evolution, and grow of academic liberties. A new trend of life, and new ways of transmitting teachings, knowledge and praxis was underway. Contemporary progress of technology in history has always had different and strange encounters. We argue that a milestone in progress has been made when great ideas and development of technology was involved in process of progress, with favourable and mutual respect on both crucial occurrences.

According to Card et.al, in The Psychology of Human-Computer Interaction, it is important to design interactive computer systems which are efficient and friendly-user in order for the people to understand the potential benefits of computer based tools. They further argue that, "although modern cognitive psychology contains a wealth of knowledge of human behaviour, it is not a simple matter to bring this knowledge to bear on the practical problems of design, to build an applied psychology that includes theory, data, and knowledge" (Card et al, 1983). Furthermore, Hewett, et.al, in Curricula for Human-Computer Interaction argued that: "Because human-computer interaction studies a human and a machine in communication, it draws from supporting knowledge on both the machine and the human side. On the machine 
side, techniques in computer graphics, operating systems, programming languages, and development environments are relevant. On the human side, communication theory, graphic and industrial design disciplines, linguistics, social sciences, cognitive psychology" (Hewett, 1992).

\section{Method}

The study presented in this paper reflects on the conceptual methods in art, architecture, creativity and innovation in academic education, emphasizing interactive teaching issues and partnership learning methods. The research methods consist of empirical observation carried out during 25 years of experience in academia, and direct observation of teaching methods, and direct observation of teaching methods. To receive a clearer data, exploring was made within department of architecture, Faculty of Civil Engineering and Architecture, in the context of the revision process of curricula within adapted academic development strategies in the University of Prishtina. Artistic component in architectural studies was explored through literature review and from the point of a retrospective review of timeline documentations, graphic documentations, workshops, and hand drawings of the students of the department of architecture in the University of Prishtina. Additional data was provided from: maps, 3D compositions of urban structure of University Campus, pioneer steps of sustainable architectural design, the contemporary building systems as a part of curricula, local environment features, and attributes of spatial planning of city of Prishtina. With this paper the objective was to present a retrospective of evolution of architectural design in above mentioned faculty, and academia. Hence, to describe teaching methods with the emphasis on creativity through art, digital era, and innovation in education. Moreover, it should be a significance value to argue that the complexity and varieties of actual situation cannot be fully portrayed, without a detailed multidimensional and multidisciplinary academic approach.

\section{Discussions}

Since the first appearance of possibilities that architects can visualize their own ideas, and designs with computers or computations with machines, a new way of thinking has begun, obviously, very hard in beginning. This process of artistic expression with digital tools, was looked as a heresy among orthodoxy hand drawing architects. But, new digital era offered enormous varieties and creative possibilities, which enabled the production of a rather same architectural model, now with infinite variations and aided with computational algorithms. Such digital models and patterns generated by software algorithms had evolved into much more realistic models. The philosophy and common acceptance of what is design is in constant evolution; we think here about a second industrial revolution, or just about a digital and different way of thinking. According to Terzidis (2006): "Such a possibility opens enormous potential than has not been previously possible. Rather than utilizing mere human-based intelligence in resolving design problems, a complementary synergetic 
relationship between humans and computers becomes possible. Ideally, in such a framework of students and teachers, both parties can contribute each one's unique strengths in an attempt to seek, explore, invent, or discover principles and methods of design. Computing becomes the essential link between the two systems, teaching and learning"

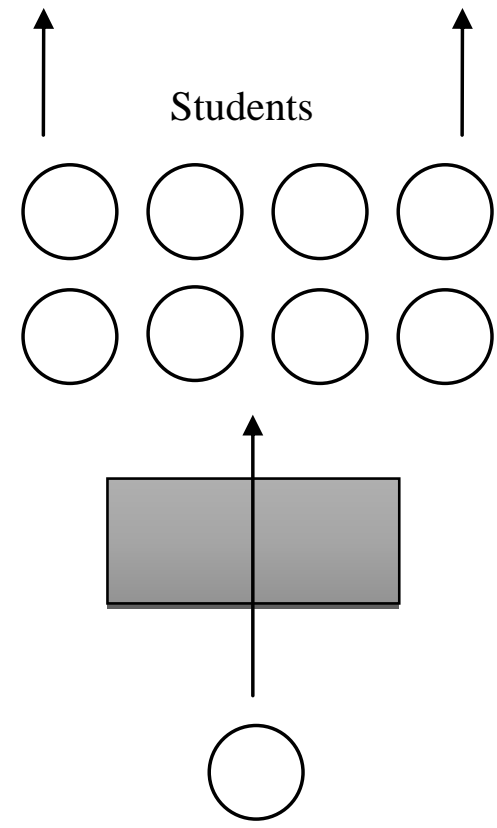

a. Lecturer

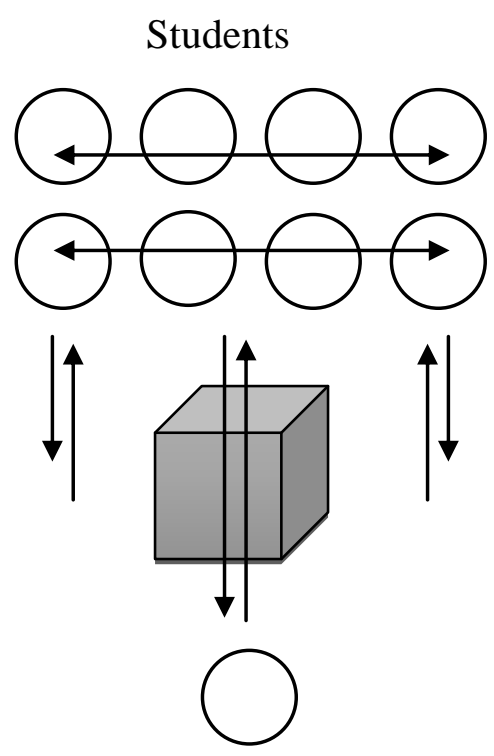

b. Lecturer

Figure 1. Interactive learning, with a model as an artifact in architectural studies, (a) and (b).

(Source: Authors, 2016)

In addition of design processes and creative impacts which the design is fundamentally refined to do, Simon also has argued this phenomenon: "Design is indeed a ubiquitous activity. In the physical world every artifact, a miniature silicon sensor for invasive blood pressure monitoring, an automobile, or a building, is the result of some kind of design activity. Any problem solving situation in which there exists an element of the unknown, such as lack of information or incomplete knowledge of the relationships among issues, involves an intellectual effort that can be categorized as design" (Simon, 1996). Modeling and learning architecture, from this context, we can count many possibilities to improve the creative artistic processes.

Therefore, according to the four key features, we can simulate relevant scenarios:

- Idea generation and possibilities

- Improvement in design and conceptual systems

- Research modeling in early stages

- Generation a various SWOT analysis and better designing 


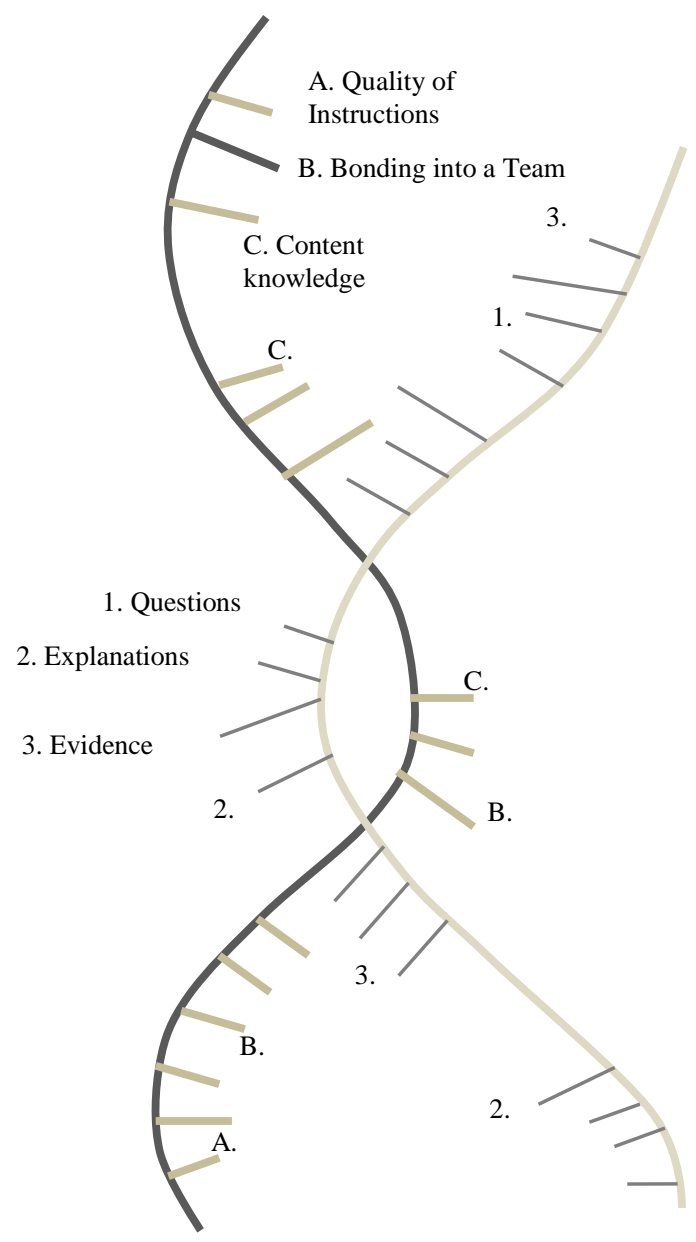

Figure 2. Forming a evolutive partnership, student and teachers. (Source: Authors, 2016)

In Figure 1-a, we can clearly observe that there is one-way communication between lecturer and students, which is not the case in Figure 1b, where communication between students and lecturers are interactive, thus, forming active partnership. In terms of integration, an integrated process of organizing partnership into a functional system is a system that requires solutions for problems, adapting and evolving strategies. Integrated framework process implies teamwork between students and teachers, with priorities clearly identified, which were in the process formulated in enough iterations, seeking best solutions to the academic and professional problems. According to the result presented in Table 1, there is a lack of variety of courses in organization of studies, therefore we need a substantial rethinking of what we have to offer as an academia and teaching staff. Current issues of improving the teaching quality and the introduction of completely new concepts, demands a new fundamentally approach of integrated and holistic engaging for both students and teachers into a group to respond to new challenges and completely a new style of living.

Table 1. Students' satisfaction with current study programme by degree studied for. (Source: Eurostudent.eu/113, 2016.) 


\begin{tabular}{|c|c|c|c|c|}
\hline & (very) well & fairly satisfied & (some) dissatisfied & total \\
\hline & percent & percent & percent & percent \\
\hline 1. Quality of teaching & 48.9 & 33.5 & 17.6 & 100 \\
\hline $\begin{array}{l}\text { 2. Organization of } \\
\text { studies }\end{array}$ & 41.6 & 31.4 & 27 & 100 \\
\hline 3. Variety of courses & 26 & 23 & 51 & 100 \\
\hline 4. Study facilities & 38.6 & 23 & 38.4 & 100 \\
\hline
\end{tabular}

The process of integrating aims to include all possible attributes of the problem, so that any decision in the design process has to identify as many phenomena of action. The process is associated with activities of all parties involved in the project and therefore has the role of transforming the nature of teaching, respectively, adopting a new approach to solving architectural problems depending on the current situation and specific requirements.

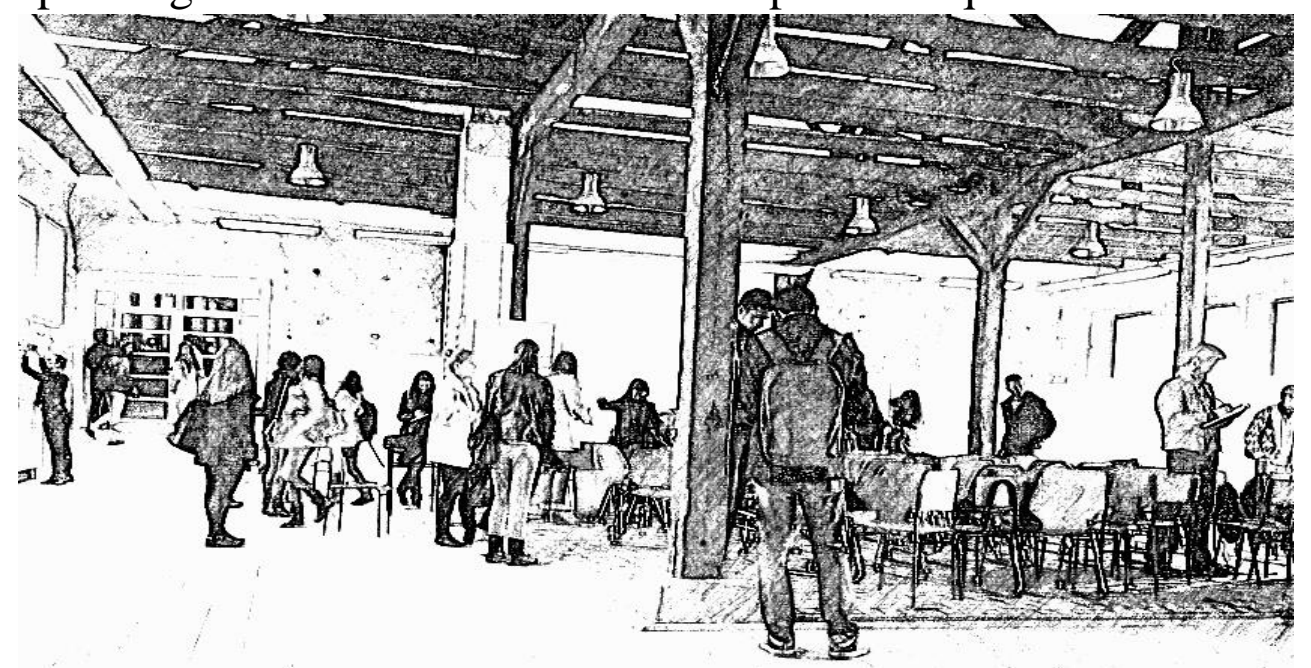

Figure 3. Students and teachers in interactive architecture. (Source: Authors, 2016)

"The average teacher explains complexity; the gifted teacher reveals simplicity." [Robert Brault] "Education, of course, is always based on what was. Education shows you what has been and leaves you to make the deduction as to what may be. Education as we pursue it cannot prophesy, and does not." [Frank Lloyd Wright, 1955.]

The architectural design has always been a pioneer of social change on basis of what is called the modern and style. In terms of quality of life, the integrated process a cooperation between students and teachers, will try to find the best solutions available for specific architectural problem, given the fact that never before as today we have multifunctional and hybrid buildings - structures that are a result of the new millennium, globalization, and trends of time paired with technology advancement. 

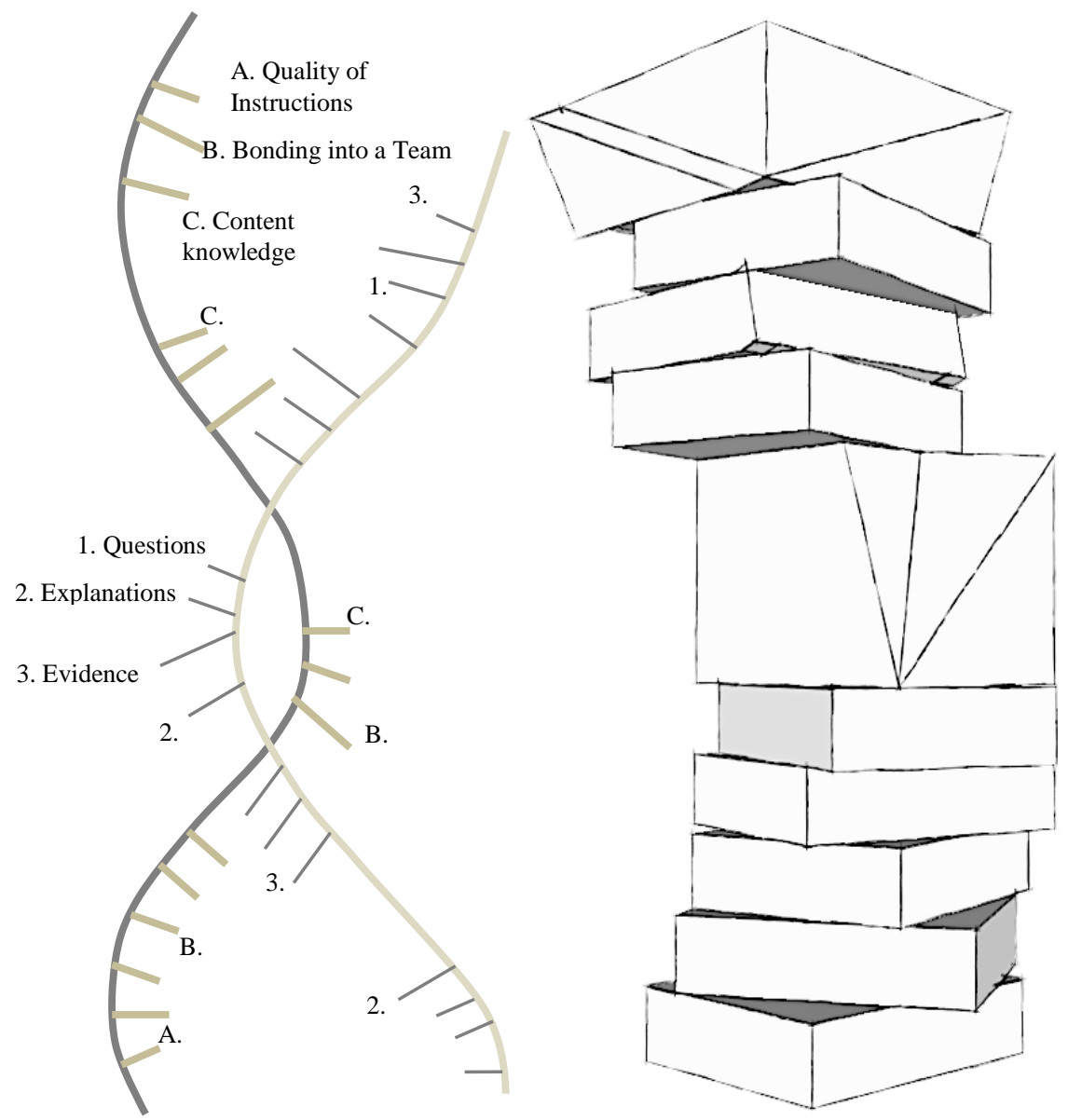

Figure 4. Structure of evolutive partnership presented as result in architecture modeling. (Source: Authors, 2016)

Therefore, those phenomena realistically impact in global market and effects on economics in the region and abroad. So a whole system is holistically interacting with a wide subsystem that forms global market. Today, before students stand a new structure of social challenges where student is a proactive key factor of future pedagogy, therefore, this challenge does redefine attributes in relationships between students and teachers in a wide space of interacting academic system.

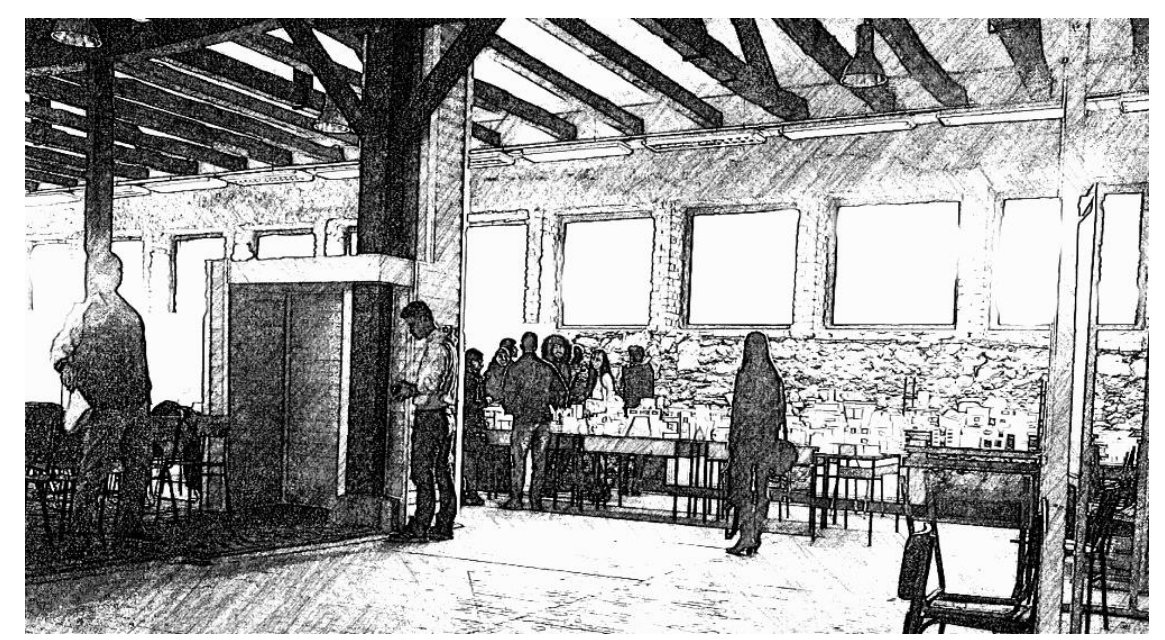

Figure 5. Modelarium - Modeling within interactive architecture. (Source: Authors, 2016) 


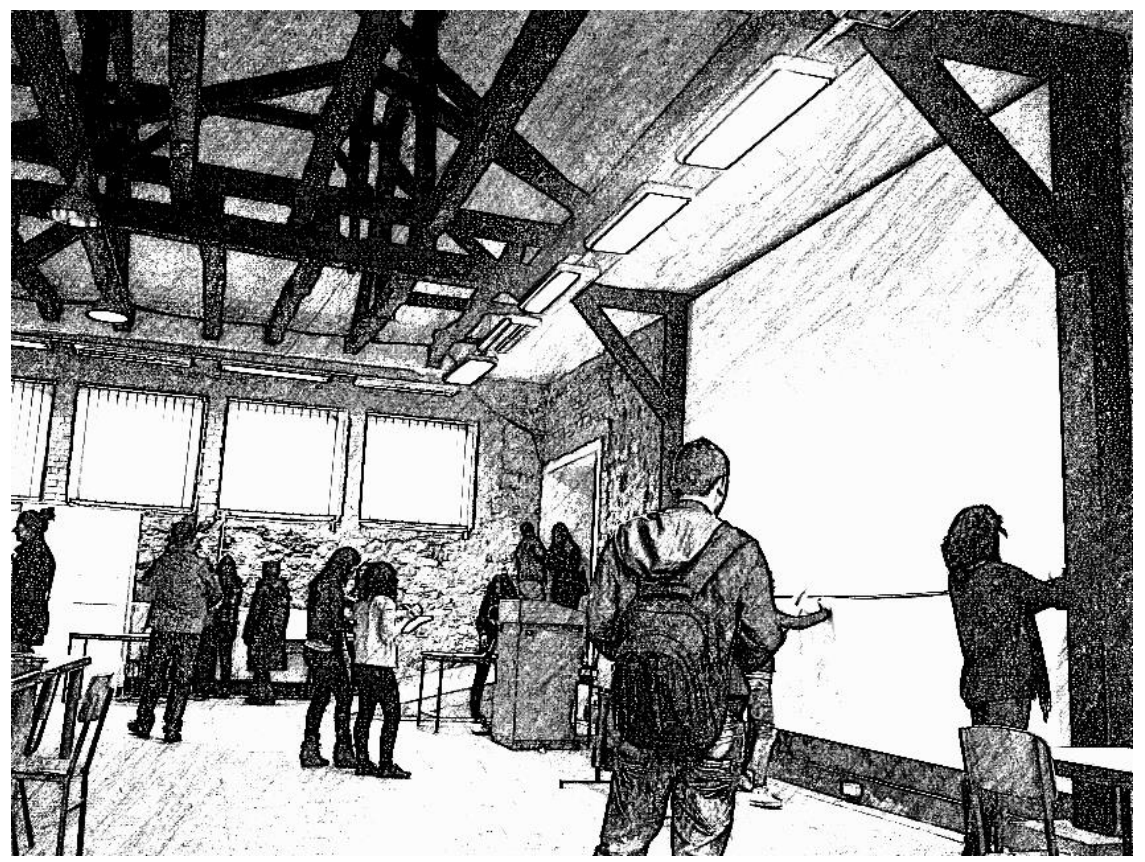

Figure 6. Modelarium - Partnership in active learning. (Source: Authors, 2016)

This was validated and pursued by many countries in Europe, basing their arguments on the need to address the demands imposed by the European educational standards and in accordance with Bologna and Lisbon conventions. According to Paşca (2006, p. 253) "The compatibilisation of university paths in creating the curricula must consider the competences which are to be acquired." She further argues that the responsibility for such undertaking "belongs equally to the institutions providing academic programs, but also to the Romanian Agency for Quality Assurance in Higher Education". This conceptual and contemporary academic framework must also be encouraged and implemented in Kosovo public universities, as well as in private colleges.

Table 2. Bachelor students' assessment of chances on labor market after graduation from current programme by field of study. (Source: Eurostudent.eu/119, 2016.).

\begin{tabular}{l|llllll} 
& $\sum$ & education & humanities & social & natural & engineering \\
\hline & $\%$ & $\%$ & $\%$ & $\%$ & $\%$ & $\%$ \\
\hline (very) good & 18.6 & 14.1 & 15.6 & 18 & 25.9 & 23.5 \\
\hline fair & 25.6 & 28.2 & 25.5 & 23.7 & 22.4 & 31.9 \\
\hline (very) poor & 44.6 & 46.4 & 46.5 & 50 & 41.4 & 34.7 \\
\hline unable to rate & 11.2 & 11.3 & 12.4 & 8.2 & 10.3 & 10 \\
\hline total & 100 & 100 & 100 & 100 & 100 & 100
\end{tabular}

According to the result presented in Table 2, there is a good belief of chances on labor market after graduation from current study program on field of natural and engineering sciences. "The fact is, thinking statistically is a life skill, like being able to speak your native language." (Fisher, 2013). Moreover, on actual contemporary art trends, there will be more active participation of passive 
partakers, thus: "the future art public won't be a simple passive receiver, easy to manipulate, but, through a harmonious development of the soul functions and of the intellectual abilities, it will be able to develop its own creative, response and selection capacities for the messages coming from the social environment, messages that can distort the perception of reality and of internal representations" (Iftimi, 2016, p. 175).

\section{Conclusions}

The current state of academia and pedagogy requires specific responsibilities and activities, especially when the state is directly linked to the quality of teaching and future challenges of the students. Formally fulfilling legal academic standards cannot be expected to solve comprehensive and future challenges, associated with the development of technology, life style, real issues and global world trends. Findings indicate that through artistic concepts of "Modelarium" as an unconventional learning space, a tool and space that enables the partnership. An informal meeting place for artistic interaction, but, concurrently it is a formal part of the educational system in architectural studies, a strategy by which we can bring more: time, conceptual awareness of space and interactive teaching in architecture, which bonds multidimensional threads between students and teachers. Thus, one and the same, and partially new strategy, cannot respond to all specific problems faced by day to day student's issues. Therefore, new teaching strategies must involve a new partnership, a brand new and more redefining role as a holistic system, as a response to less functional academic system. Partnership, a new symbiosis between students and teachers must prevail, working together simultaneously on continuous improvement of process.

\section{Bibliography}

1. Card, S., Moran, K.S., Newell, A. (1983). The Psychology of HumanComputer Interaction. New Jersey: Lawrence Erlbaum Associates. Reprinted: (2008). CRC Press, New York, NY 10016.

2. Cronin, K. (2008). Transdisciplinary research and sustainability. New Zealand: MoRST.

3. Cullingford, C., \& Haq, N. (2009). Computers, Schools and Students, The Effects of Technology. Abingdon: Routledge.

4. EuroStudent (2016). Retrieved from http://database.eurostudent.eu/113, http://database.eurostudent.eu/export/113, http://database.eurostudent.eu/export/119

5. Fisher, N.I. (2013). Communication about professional statisticians within and outside the profession: key messages to key audiences. In Proceedings 59th ISI World Statistics Congress, 25-30 August 2013, Hong Kong (Sess. IPS047).

6. Hewett, B., Card, C., Gasen, M., Perlman, S. \& Verplank, M. (1992)."ACM SIGCHI Curricula for Human-Computer Interaction". ACM SIGCHI. 
7. Iftimi-Aproposoaie, A.M. (2016). The openness of the visual art curriculum towards a new visual art language. Review of Artistic Education, 11/12 2016, 175-182. DOI: 10.1515/rae-2016-0021

8. Kargon, R., Molella, A. (2008). Invented Edens. Invented-Cities of the Twentieth Century. Massachusetts: Massachusetts Institute of Technology.

9. Kolarević, B. (2005). Architecture in the Digital Age: Design and Manufacturing. Revised ed., Taylor \& Francis.

10. Paşca, E. M. (2016). Variables and constants in the curriculum for the music specializations of the Romanian University Education. Review of Artistic Education, 11/12, 253-262. DOI: 10.1515/rae-2016-0030

11. Samuelsson, L. (2008). The moral status of nature. Umeå, Sweden: Umeå University.

12. Sears, A., Jacko, A. J. (2009). Human-Computer Interaction. Taylor \& Francis.

13. Sebestyen, G. \& Pollington, Ch. (2003). New Architecture and Technology. Oxford: Architectural Press, Elsevier.

14. Simon, H. A. (1996). The Sciences of the Artificial, (3ed.), MIT Press, Cambridge, Massachusetts.

15. Terzidis, K. (2006). Algorithmic Architecture. New York: Architectural Press. Taylor \& Francis.

16. Toriya, H. (2008). 3D Manufacturing Innovation. London: Springer-Verlag. DOI: $10.1007 / 978-1-84800-038-4$ 